\title{
COMUNICAÇÃO
}

\section{RENDIMENTO PRODUTIVO E ECONÔMICO DO FEIJÃO-CAUPI EM FUNÇÃO DE DOSES DE POTÁSSIO}

\author{
Productive and economic yield of cowpea bean as a function of levels of potassium
}

\author{
Ademar Pereira de Oliveira ${ }^{1}$, Jandiê Araújo da Silva ${ }^{2}$, Edson Batista Lopes ${ }^{3}$, \\ Erllens Éder Silva ${ }^{4}$, Lucia Helena Avelino Araújo ${ }^{5}$, Valéria Veras Ribeiro ${ }^{6}$
}

\begin{abstract}
RESUMO
O feijão-caupi [Vigna unguiculata (L) Walp], também conhecido como feijão-macassar, feijão-de-corda ou fradinho é uma das principais culturas do Nordeste do Brasil. Objetivou-se, com este trabalho, avaliar o efeito da adubação potássica sobre o rendimento produtivo e econômico do feijão-caupi, cultivar Pitiuba. O trabalho foi realizado na Universidade Federal da Paraíba, em Areia (PB), em Neossolo Regolítico Psamítico típico, no período de julho a setembro de 2005. O delineamento experimental empregado foi o de blocos casualizados, com seis tratamentos $\left(0,50,100,150,200\right.$ e $250 \mathrm{~kg} \mathrm{ha}^{-1}$ de $\left.\mathrm{K}_{2} \mathrm{O}\right)$ e quatro repetições. Cada parcela continha 40 plantas espaçadas de $0,80 \mathrm{~m}$ x $0,40 \mathrm{~m}$. A produção máxima de vagens por planta $(285 \mathrm{~g})$ de grãos verdes $(143 \mathrm{~g})$ e de grãos secos $(120 \mathrm{~g})$ foram obtidas, respectivamente, com 160, 153 e $200 \mathrm{~kg} \mathrm{ha}^{-1} \mathrm{de} \mathrm{K}_{2} \mathrm{O}$. As doses de 210, 151 e $170 \mathrm{~kg} \mathrm{ha}^{-1}$ de $\mathrm{K}_{2} \mathrm{O}$, respectivamente, foram responsáveis pelas produtividades máximas de $4,18 \mathrm{t} \mathrm{ha}^{-1}$ de vagens, $3,48 \mathrm{t} \mathrm{ha}^{-1}$ de grãos verdes e de $1,89 \mathrm{t} \mathrm{ha}^{-1}$ de grãos secos. A dose de máxima eficiência econômica para a produtividade de grãos secos foi de $141 \mathrm{~kg} \mathrm{ha}^{-1} \mathrm{de} \mathrm{K}_{2} \mathrm{O}$, com produtividade de $1,87 \mathrm{t} \mathrm{ha}^{-1}$.
\end{abstract}

Termos para indexação: Vigna unguiculata, fertilização potássica, produção de grãos verdes e secos.

\section{ABSTRACT}

Cowpea bean [Vigna unguiculata (L) Walp] is one the main crops in the Northeast region of Brazil. With the objective of evaluating the effect of potassium fertilization on cowpea bean cv. Pitiúba, an experiment was carried out at Federal University of Paraíba, in Areia (PB), Brazil, on a Quartz Psamment soil, from July to September 2005. The experimental design was the randomized blocks, with six treatments $\left(0,50,100,150,200\right.$, and $\left.250 \mathrm{~kg} \mathrm{ha}^{-1} \mathrm{~K}_{2} \mathrm{O}\right)$, and four replications. Each plot contained 40 plants spaced $0.80 \mathrm{~m} \mathrm{x} 0.40 \mathrm{~m}$. The maximum yield of pods per plant $(285 \mathrm{~g})$, green grains $(143 \mathrm{~g})$ and dry grains $(120 \mathrm{~g})$ were obtained with 160 , 153 and $200 \mathrm{~kg} \mathrm{ha}^{-1} \mathrm{~K}_{2} \mathrm{O}$, respectively. The levels of 210,151 , and $170 \mathrm{~kg} \mathrm{ha}^{-1} \mathrm{~K}_{2} \mathrm{O}$ were responsible for the maximum yields of 4.18 $\mathrm{t} \mathrm{ha}^{-1}$ of pods, $3.48 \mathrm{tha}^{-1}$ of green grains, and $1.89 \mathrm{t} \mathrm{ha}^{-1}$ of dry grains, respectively. The maximum level of economical efficiency for the yield of dry grains was $141 \mathrm{~kg} \mathrm{ha}^{-1} \mathrm{~K}_{2} \mathrm{O}$, with a yield of $1.87 \mathrm{t} \mathrm{ha}^{-1}$.

Index terms: Vigna unguiculata, potassium fertilization, production of green and dry grains.

(Recebido em 20 de junho de 2007 e aprovado em 10 de março de 2008)

O caupi [Vigna unguiculata (L) Walp], também conhecido por feijão-macassar ou feijão-de-corda, é uma das opções de renda e alimento para a população do Nordeste do Brasil, que o consome na forma de grãos maduros ou grãos verdes. Na Paraíba, é cultivado em quase todas as microrregiões, onde ocupa $75 \%$ das áreas de cultivo com feijão. Assim, ele exerce efetiva participação na dieta alimentar da população, por constituir-se uma excelente fonte de proteínas e carboidratos de baixo custo (IBGE, 1996; SILVA \& OLIVEIRA, 1993).

Embora o feijão-caupi seja considerado uma cultura tropical, compatível com as condições ecológicas locais, ainda apresenta baixa produtividade, tanto no sistema de cultivo solteiro como consorciado (MIRANDA et al., 1996),

\footnotetext{
'Doutor em Agronomia, Professor Associado I - Departamento de Fitotecnia - Centro de Ciências Agrárias/CCA - Universidade Federal da Paraíba/ UFPB - Campus II - Cidade Universitária - Cx. P. 02 - 58397-000 - Areia, PB - ademar@cca.ufpb.br

Engenheiro Agrônomo, Mestre - Departamento de Fitotecnia - Centro de Ciências Agrárias/CCA - Universidade Federal da Paraíba/UFPB - Campus II - Cidade Universitária - Cx. P. 02 - 58397-000 - Areia, PB - agrojand@yahoo.com.br

${ }^{3}$ Doutor - Empresa Estadual de Agropecuária da Paraíba S/A EMEPA-PB - Rua Vereador Benedito Mota, 885 - Alto Branco - $58102-520$ - Campina Grande, PB - edsonbatistalopes@hotmail.com

${ }^{4}$ Doutorando em Agronomia - Programa de Pós-Graduação em Agronomia - Centro de Ciências Agrárias/CCA - Universidade Federal da Paraíba/UFPB Campus II - Cidade Universitária - Cx. P. 02 - 58397-000 - Areia, PB - erllens eder@hotmail.com

${ }^{5}$ Mestre - Departamento de Entomologia - Empresa Brasileira de Pesquisa Agropecuária/EMBRAPA - Centro Nacional de Pesquisa de Algodão - Rua Oswaldo Cruz, 1143 - Centenário - Cx. P. 174 - 58107-720 - Campina Grande, PB - lucia@cnpa.embrapa.com.br

${ }^{6}$ Farmacêutica, Doutora em Agronomia - Departamento de Biologia/DB - Universidade Estadual da Paraíba/UEPB - Avenida das Baraúnas, 351 Bodocongó - 58101-001 - Campina Grande, PB - valeria vr@hotmail.com
} 
decorrente do plantio de cultivares tradicionais com baixa qualidade agronômica e ausência de um programa de manejo adequado de nutrientes no solo (OLIVEIRA et al., 2001). Alguns autores afirmam que para obterem-se altos rendimentos de caupi, se faz necessária a utilização de sementes de qualidade, e relatam o fornecimento de uma adubação equilibrada em matéria orgânica e NPK (MAIA et al., 1986; OLIVEIRA et al., 2001).

O potássio tem inúmeras funções na planta, destacando-se, principalmente, a ativação de vários sistemas enzimáticos, muito deles participantes dos processos de fotossíntese e respiração. Plantas deficientes caracterizam-se por crescimento lento, raízes pouco desenvolvidas, caules fracos e muito flexíveis e mais suscetíveis a ataques de doenças, além de prejudicarem a formação de sementes e frutos com menor tamanho e com menor intensidade de cor (ERNANI et al., 2007).

O feijão-comum pode absorver, em condições favoráveis, quantidades significativas de potássio (ROSOLEM, 1996), proporcionando melhor desenvolvimento dos grãos na maturação e no vigor da semente (OLIVEIRA et al., 1996). No caupi, o potássio é o nutriente extraído e exportado em maiores quantidades, por isso na maioria dos solos onde é explorado comercialmente são encontrados teores baixos desse nutriente. Contudo, raramente se observam respostas significativas do potássio sobre o seu rendimento, provavelmente porque o valor considerado crítico para o seu desenvolvimento normal é baixo, entre 20 e $40 \mathrm{~kg}$ $\mathrm{ha}^{-1}$, mas o suficiente para provocar altas concentrações desse nutriente no tecido das plantas (MELO et al., 2005). Objetivouse, com este trabalho, objetiva-se com este trabalho, avaliar o efeito da adubação potássica sobre o rendimento produtivo e econômico do feijão-caupi, cultivar Pitiuba.

$\mathrm{O}$ trabalho foi conduzido Universidade Federal da Paraíba, em Areia - PB, em Neossolo Regolítico Psamítico Típico textura franca (EMBRAPA, 1999), entre julho e outubro de 2005 . A temperatura média $\left(\mathrm{em}{ }^{\circ} \mathrm{C}\right.$ ), a precipitação pluvial (em mm) e a umidade relativa (em \%) do período de execução do experimento foram, respectivamente: julho $=21,3 ; 90,7 ; 85$; agosto $=21,2 ; 233$; 89 ; setembro $=22,4 ; 85,7 ; 80$ e outubro $=23,4 ; 102 ; 73$. As análises químicas da camada do solo de $0-20 \mathrm{~cm}$, realizada segundo Embrapa (1997), deram estes resultados: $\mathrm{pH}=$ 6,$3 ; \mathrm{P}=93,0 \mathrm{mg} \mathrm{dm}^{-3} ; \mathrm{K}=0,16 \mathrm{cmol}_{\mathrm{c}} \mathrm{dm}^{-3} ; \mathrm{Al}^{+3}=0,0 \mathrm{cmol}_{c}$ $\mathrm{dm}^{-3} ; \mathrm{Ca}^{+2}=2,80 \mathrm{cmol}_{\mathrm{c}} \mathrm{dm}^{-3} ; \mathrm{Mg}^{+2}=1,20 \mathrm{cmol}_{\mathrm{c}} \mathrm{dm}^{-3}, \stackrel{\mathrm{e}}{\mathrm{e}}$ matéria orgânica $=10,40 \mathrm{~g} \mathrm{dm}^{-3}$. O esterco bovino utilizado possuía as seguintes características químicas: $\mathrm{P}=5,2 \mathrm{~g} \mathrm{~kg}$ ${ }^{1} ; \mathrm{K}=4,9 \mathrm{~g} \mathrm{~kg}^{-1} ; \mathrm{N}=3,2 \mathrm{~g} \mathrm{~kg}^{-1}$, matéria orgânica $=112,07 \mathrm{~g}$ $\mathrm{dm}^{-3}$ e relação $\mathrm{C} / \mathrm{N}=14 / 1$.
Adotou-se o delineamento experimental de blocos casualizados com seis doses de $\mathrm{K}_{2} \mathrm{O}(0,50,100,150,200 \mathrm{e}$ $250 \mathrm{~kg} \mathrm{ha}^{-1}$ ), na forma de cloreto de potássio, e quatro repetições. As parcelas foram compostas de 40 plantas, espaçadas de $0,8 \mathrm{~m}$ entre fileiras e $0,4 \mathrm{~m}$ entre plantas, sendo 20 plantas empregadas para avaliar o rendimento de vagens e de grãos verdes e 20 para avaliar o rendimento de grãos secos. Na adubação de plantio foram fornecidos 100 $\mathrm{kg} \mathrm{ha}^{-1} \mathrm{de}$ superfosfato simples, $20 \mathrm{tha}^{-1}$ de esterco bovino e 50\% das doses de $\mathrm{K}_{2} \mathrm{O}$, descritas acima. Na adubação de cobertura aplicaram-se os $50 \%$ restantes das doses de $\mathrm{K}_{2} \mathrm{O}$ e $100 \mathrm{~kg} \mathrm{ha}^{-1}$ de uréia, parceladas $50 \%$ aos 20 e $50 \%$ aos 40 dias após a semeadura.

A semeadura foi realizada pelo método de semeadura direta, colocando-se duas sementes por cova da cultivar Pitiúba, efetuando-se 15 dias após o desbaste para uma planta. Essa cultivar apresenta tipo de crescimento semiprostrado, com ciclo precoce, e alcança maturidade com 61 a 70 dias após a semeadura. Realizaram-se os tratos culturais recomendados para a cultura, e fez-se irrigação por aspersão nos períodos de ausência de chuvas; capinas para manter a área livre de plantas invasoras e pulverizações com deltamethrina (126 $\left.\mathrm{ml} \mathrm{ha}^{-1}\right)$, para controlar cigarrinhaverde (Empoasca kraemeri).

As colheitas, em número de seis, foram realizadas manualmente. Nas plantas selecionadas, para avaliar-se o rendimento de vagens e de grãos verdes, as colheitas foram efetuadas quando as vagens estavam imaturas; enquanto nas selecionadas para avaliar-se o rendimento de grãos secos, as colheitas ocorreram à medida que as vagens secavam. Foram avaliadas as produções por planta e a produtividade de vagens e de grãos verdes e secos. Os dados foram submetidos às análises de variância e de regressão, utilizando-se o software SAEG (UFV, 2000), sendo selecionado para expressar o comportamento das doses de $\mathrm{K}_{2} \mathrm{O}$ sobre as características avaliadas, o modelo significativo que apresentou maior coeficiente de determinação $\left(R^{2}\right)$. Nas significâncias das análises de variância e de regressão foi considerado o nível de probabilidade de até $5 \%$, pelo teste $\mathrm{F}$.

Como o maior volume de comercialização do feijãocaupi é na forma de grãos secos, calculou-se a dose de máxima eficiência econômica de $\mathrm{K}_{2} \mathrm{O}$ para sua produção igualando-se à derivada primeira da equação de regressão à relação entre preços do insumo $\left(\mathrm{R} \$ / \mathrm{kg}\right.$ de $\left.\mathrm{K}_{2} \mathrm{O}\right)$ e do produto (R $\$ / \mathrm{kg}$ de grãos secos) (NATALE et al., 1996; RAIJ, 1991). Os preços adotados foram aqueles vigentes em Areia - PB, em outubro de 2005:0 R0\$2,50/kg de $\mathrm{K}_{2} \mathrm{Oe} \mathrm{R} \$ 1,50 /$ $\mathrm{kg}$ de grãos secos. O preço do quilograma de vagens $(\mathrm{R} \$$ $1,00 / \mathrm{kg}$ ) correspondeu ao recebido pelo produtor, no ano 
de 2006. No entanto, a fim de atenuar os problemas de variação cambial, trabalhou-se com uma relação de troca ao invés de moeda corrente (NATALE et al., 1996), procurando-se, assim, dados mais estáveis. Portanto, a "moeda" utilizada nos cálculos, foi o próprio grão, considerando-se a seguinte relação de equivalência: quilograma de $\mathrm{K}_{2} \mathrm{O} / \mathrm{kg}$ de grãos igual a 1,7. A dose mais econômica foi calculada com base na derivada da equação de regressão entre as produtividades de grãos secos e as doses de $\mathrm{K}_{2} \mathrm{O}$ por meio da relação de $\mathrm{dy} / \mathrm{dx}=\mathrm{a}_{1}+2 \mathrm{a}_{2} \mathrm{x}$. As doses mais econômicas ( $x^{\prime}$ ) foram calculadas por:

$$
\mathrm{x}^{\prime}=\underline{\mathrm{a}}_{1}-\frac{\text { relação de equivalência, }}{2\left(-\mathrm{a}_{2}\right)}
$$

em que:

x' representa a dose econômica;

$a_{1}$ a taxa de incremento de produção e

$\mathrm{a}_{2}$, o ponto de máxima produção.

Houve respostas quadráticas significativas das características avaliadas $(\mathrm{P}<0,05)$ às doses de $\mathrm{K}_{2} \mathrm{O}$.

As produções máximas por planta de vagens verdes (285 g), de grãos verdes (143 g) e de grãos secos $(120 \mathrm{~g})$ foram obtidas, respectivamente com 160, $153 \mathrm{e}$ $200 \mathrm{~kg} \mathrm{ha}^{-1}$ de $\mathrm{K}_{2} \mathrm{O}$ (Figura 1). Oliveira et al. (2007) estudaram feijão-vagem em função de doses $\mathrm{K}_{2} \mathrm{O}$ nas mesmas condições e local do presente estudos. Obtiveram produção máxima de vagens por planta (171 g) na dose $173 \mathrm{~kg} \mathrm{ha}^{-1}$ de $\mathrm{K}_{2} \mathrm{O}$ e Araújo et al. (2001) de 299 g com a adição de $170 \mathrm{~kg} \mathrm{ha}^{-1}$ de $\mathrm{K}_{2} \mathrm{O}$ em solo com $153 \mathrm{mg}$ $\mathrm{dm}^{-3}$ de potássio residual, em condições de alta precipitação. Provavelmente, a resposta às doses mais baixas de $\mathrm{K}_{2} \mathrm{O}$, verificadas para obtenção da produção máxima de vagens por planta, deva-se às condições climáticas, porque, no presente estudo, a precipitação pluvial mensal durante a condução da cultura variou de 20 a $30 \mathrm{~mm}$ mensal, o que pode ter reduzido à lixiviação do potássio.

As doses de 210, 151 e $170 \mathrm{~kg} \mathrm{ha}^{-1}$ de $\mathrm{K}_{2} \mathrm{O}$, respectivamente, foram responsáveis pelas produtividades máximas estimadas de vagens verdes $\left(4,18 \mathrm{t} \mathrm{ha}^{-1}\right)$, de grãos verdes $\left(3,48 \mathrm{t} \mathrm{ha}^{-1}\right)$ e de grãos secos $\left(1,89 \mathrm{t} \mathrm{ha}^{-1}\right)$ do feijão-caupi (Figura 2). Esses resultados contradizem Melo et al. (2005), quando afirmaram que raramente o feijão-caupi responde à adubação potássica. Oliveira et al. (2003) encontraram produtividades máximas estimadas de 11; 9,3 e 3,6 t ha ${ }^{-1}$ de vagens, de grãos verdes e de grãos secos, respectivamente, com aplicação de 68 $\mathrm{kg} \mathrm{ha}^{-1}$ de cloreto de potássio em solo com $165 \mathrm{mg} \mathrm{dm}^{-3}$ de $\mathrm{K}$, evidenciando uma boa produção do caupi nas condições de Areia-PB.

A quantidade de potássio considerada crítica para o desenvolvimento normal do feijão-caupi está entre 20 e $40 \mathrm{~kg} \mathrm{ha}^{-1}$ (MELO et al., 2005). Portanto, as altas doses de $\mathrm{K}_{2} \mathrm{O}$ necessárias nessa pesquisa para proporcionar produtividades máximas, possivelmente, estejam relacionadas à eficiência das leguminosas em absorver, em condições favoráveis, quantidades significativas de potássio (ROSOLEM, 1996).

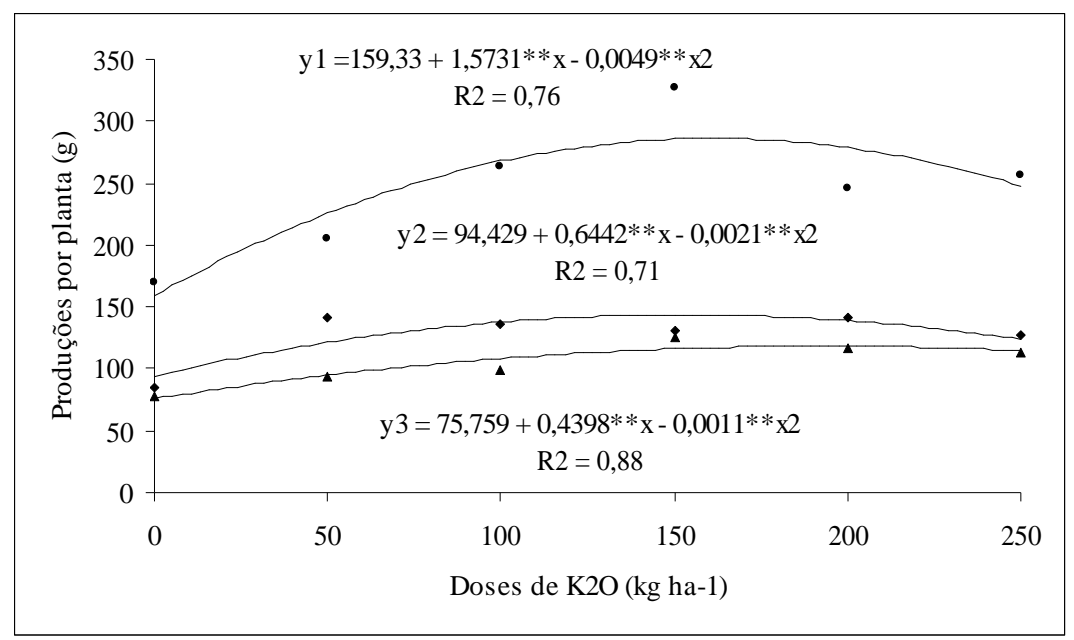

Figura 1 - Produção de vagens verdes $\left(\mathrm{y}_{1}\right)$, grãos verdes $\left(\mathrm{y}_{2}\right)$ e secos $\left(\mathrm{y}_{3}\right)$ de feijão-caupi, cultivar Pitiuba, em função das doses de $\mathrm{K}_{2} \mathrm{O}$. 


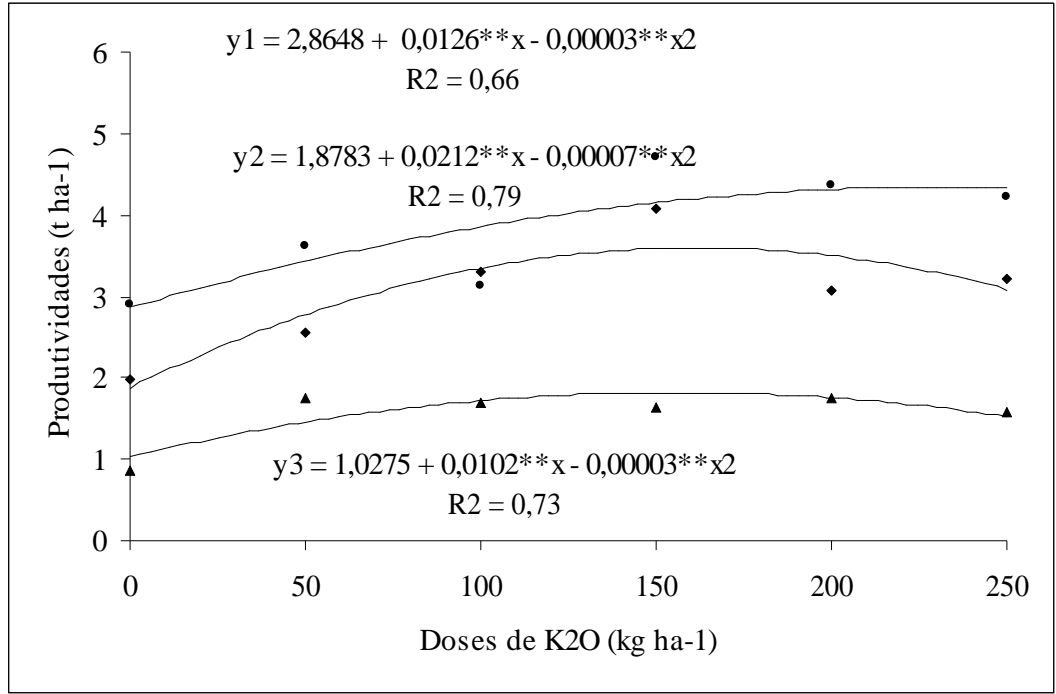

Figura 2 - Produtividade de vagens verdes $\left(\mathrm{y}_{1}\right)$, grãos verdes $\left(\mathrm{y}_{2}\right)$ e secos $\left(\mathrm{y}_{3}\right)$ de feijão-caupi, cultivar Pitiuba, em função das doses de $\mathrm{K}_{2} \mathrm{O}$.

A resposta positiva do feijão-caupi ao emprego do potássio pode ser atribuída ao fato de que, durante o crescimento e desenvolvimento das plantas, as doses de $\mathrm{K}_{2} \mathrm{O}$ juntamente com o fósforo e o esterco bovino adicionados ao solo, supriram de forma equilibrada as necessidades nutricionais da cultura. De acordo com Filgueira (2000), o fornecimento de potássio ao solo assegura às hortaliças a possibilidade de desenvolver, plenamente, o seu potencial produtivo. No feijão-comum, a deficiência de potássio retarda a maturação, proporciona perda no vigor da semente e redução no desenvolvimento dos grãos (OLIVEIRA et al., 1996).

A redução das produtividades de vagens e de grãos verdes e secos com doses de $\mathrm{K}_{2} \mathrm{O}$ acima daquelas responsáveis pelas máximas produtividades pode indicar que o excesso desse nutriente foi prejudicial ao desenvolvimento do feijão-caupi, possivelmente em consequiência direta do seu efeito antagônico, o que reduziu a absorção de outros cátions, isso é, exerceu forte efeito competitivo sobre os nutrientes $(\mathrm{Ca}, \mathrm{Mg}, \mathrm{N}$ e $\mathrm{P})$, influenciando de forma negativa o desenvolvimento fisiológico das plantas e na produção de vagens e de grãos (CARNICELLI et al., 2000). Também, possivelmente, o excesso de potássio no solo pode ter estimulado o crescimento excessivo das plantas, em detrimento à formação de vagens (JORGER, 1988).

A fórmula obtida para a dose de máxima eficiência econômica foi:

$$
\text { Dose de } \mathrm{K}_{2} \mathrm{O}=\underline{10,2-1,7}
$$

em que 1,7 é a relação entre os preços do insumo e do produto. Dessa forma, a dose mais econômica de $\mathrm{K}_{2} \mathrm{O}$ foi de $141 \mathrm{~kg} \mathrm{ha}^{-1}$, com produção de $1870 \mathrm{~kg} \mathrm{ha}^{-1}$ de grãos secos, o que representa um incremento de $846 \mathrm{~kg} \mathrm{ha}^{-1} \mathrm{de}$ grãos, em relação à ausência de $\mathrm{K}_{2} \mathrm{O}$. Deduzido da quantidade de grãos secos $\left(235 \mathrm{~kg} \mathrm{ha}^{-1}\right)$, necessário para aquisição de $141 \mathrm{~kg} \mathrm{ha}^{-1}$ de $\mathrm{K}_{2} \mathrm{O}$, resultou em superávit de $611 \mathrm{~kg} \mathrm{ha}^{-1}$, o que representa um ganho adicional de mais de 100 sacas de $60 \mathrm{~kg}$. A dose mais econômica apresentou $82 \%$ daquela responsável pela produtividade máxima, o que pode indicar a viabilidade econômica do emprego de potássio no cultivo de feijão-caupi. Objetivou-se, com este trabalho, avaliar o efeito da adubação potássica sobre o rendimento produtivo e econômico do feijão-caupi, cultivar Pitiuba.

$\mathrm{O}$ feijão-caupi exige quantidades diferentes de $\mathrm{K}_{2} \mathrm{O}$ para produção de vagens, grãos verdes e grãos secos, 210, 151 e $170 \mathrm{~kg} \mathrm{ha}^{-1}$, respectivamente. A dose mais econômica para a produção de grãos secos no feijão-caupi foi de $141 \mathrm{~kg} \mathrm{ha}^{-1}$ de $\mathrm{K}_{2} \mathrm{O}$ Portanto, o emprego do potássio aumentou o rendimento do feijão-caupi.

\section{REFERÊNCIAS BIBLIOGRÁFICAS}

ARAÚJO, J. S.; OLIVEIRA, A. P.; SILVA, J. A. L.; RAMALHO, C. I.; COSTA NETO, F. L. Rendimento do feijão-vgem cultivado com esterco suíno e adubação mineral. Revista Ceres, Viçosa, v. 48, n. 278, p. 501-510, 2001. 
CARNICELLI, J. H.; PEREIRA, P. R. G.; FONTES, P. C. R.; CAMARGO, M. I. Índices de nitrogênio na planta relacionados com a produção comercial de cenoura. Horticultura Brasileira, Brasília, v. 18, p. 808-810, p. 8, 2000. Suplemento.

\section{EMPRESA BRASILEIRA DE PESQUISA}

AGROPECUÁRIA. Centro Nacional de Pesquisa de Solos. Manual de métodos de análise de solo. Rio de Janeiro, 1997. 212 p (Documento, 1).

\section{EMPRESA BRASILEIRA DE PESQUISA}

AGROPECUÁRIA. Centro Nacional de Pesquisa do Solo. Sistema brasileiro de classificação de solos. Brasília, DF, 1999. 412 p.

ERNANI, P. R.; ALMEIDA, J. A.; SANTOS, F. C. Potássio. In: NOVAIS, R. F.; ALVAREZ, V. V. U.; BARROS, N. F.; FONTES, R. L. F.; CANTARUTTI, R. B.; NEVES, J. C. L. Fertilidade do solo. Viçosa: UFV, 2007. 1017 p.

FILGUEIRA, F. A. R. Novo manual de olericultura: agrotecnologia moderna na produção e comercialização de hortaliças. Viçosa: UFV, 2000. 402 p.

\section{INSTITUTO BRASILEIRO DE GEOGRAFIA E}

ESTATÍSTICA. Anuário estatístico. Rio de Janeiro, 1996.

JORGER, J. Solo: manejo e adubação. 2. ed. São Paulo: Nobel, 1988. 312 p.

MAIA, A. F.; ASSUNÇÃO, M. V.; ALVES, J. F. Influência do método de debulha e da umidade na produção de sementes de feijão de corda. Ciência Agronômica, Fortaleza, v. 17, n. 2, p. 91-100, 1986.

MELO, F. B.; CARDOSO, M. J.; SALVIANO, A. A. C. Fertilidade do solo e adubação. In: ___ FeijãoCaupi: avanços tecnológicos. Brasília, DF: Embrapa Meio-norte, 2005. p. 228-242.

MIRANDA, P.; COSTA, A. F.; OLIVEIRA, L. R.; TAVARES, J. A.; PIMENTEL, M. L.; LINS, G. M. L. Comportamento de cultivares de Vigna unguiculata (L) Walp., nos sistemas solteiro e consorciado: IV tipos ereto e semi-ereto. Pesquisa Agropecuária
Pernambucana, Recife, v. 9, p. 95-105, 1996. Edição especial.

NATALE, W.; COUTINHO, E. L. M.; BOARETTO, A.; PEREIRA, F. M. Dose mais econômica de adubo nitrogenado para a goiabeira em formação. Horticultura Brasileira, Brasilia, v. 14, n. 2, p. 196-1999, 1996.

OLIVEIRA, A. P.; ARAÚJO, J. S.; ALVES, E. U.; NORONHA, M. A. S.; CASSIMIRO, C. M.;

MENDONÇA, F. G. Rendimento de feijão-caupi cultivado com esterco bovino e adubo mineral. Horticultura Brasileira, Brasília, v. 19, n. 1, p. 81- 84, 2001.

OLIVEIRA, A. P.; SILVA, J.A.; ALVES, A. U.; DORNELES, C. S. M.; ALVES, A. U.;OLIVEIRA, A. N. P.; CARDOSO, E. A.; SILVA CRUZ, I. S. Rendimento de feijão-vagem em função de doses de $\mathrm{K}_{2} \mathrm{O}$. Horticultura Brasileira, Brasília, v. 25, n. 1, p. 29-33, 2007.

OLIVEIRA, A. P.; SILVA, V. R. F.; ARRUDA, F. P.; NASCIMENTO, I. S.; ALVES, A. U.Rendimento de feijão-caupi em função de doses e formas de aplicação de nitrogênio. Horticultura Brasileira, Brasília, v. 21, n. 1, p. 77-80, 2003.

OLIVEIRA, I. P.; ARAUJO, R. S.; DUTRA, L. G. Nutrição mineral e fixação biológica de nitrogênio. In: ARAÚJO,

R. S.; RAVA, C.; STONE, L. F.; ZIMMERMANN, M. J. O. Cultura do feijoeiro comum no Brasil. Piracicaba: Potafos, 1996. p. 169-221.

RAIJ, B. V. Fertilidade do solo e adubação. Piracicaba: Ceres Potafos, 1991. 343 p.

ROSOLEM, C. Calagem e adubarão mineral. In: ARAÚJO, R. S.; RAVA, C.; STONE, L. F.; ZIMMERMANN, M. J. Cultura do feijoeiro comum no Brasil. Piracicaba: Potafos, 1996. p. 353-390.

SILVA, P. S. L.; OLIVEIRA, C. N. Rendimentos de feijão verde e maduro de cultivares de caupi. Horticultura Brasileira, Brasília, v. 11, n. 2, p. 133-135, 1993.

UNIVERSIDADE FEDERAL DE VIÇOSA. SAEG Sistema para análise estatística. Versão 8.0. Viçosa: Fundação Artur Bernardes, 2000. 
